\title{
Erratum zu: Die Verhandlung von subjektiver Sicherheit im öffentlichen \\ Raum als Arena der Aushandlung \\ von sozialer Ordnung: Situation - \\ Organisation - Diskurs
}

\section{Erratum zu:}

\section{Kapitel 7 in: K. Miko-Schefzig, Subjektive Sicherheit in}

Situation, Organisation und Diskurs, Theorie und Praxis der Diskursforschung, https://doi.org/10.1007/978-3-658-27305-7_7

Die originale Version dieses Buches wurde mit vertauschter Abbildung publiziert. Die Abbildung auf Seite 283 ist nun korrigiert und wird wie nachstehend dargestellt.

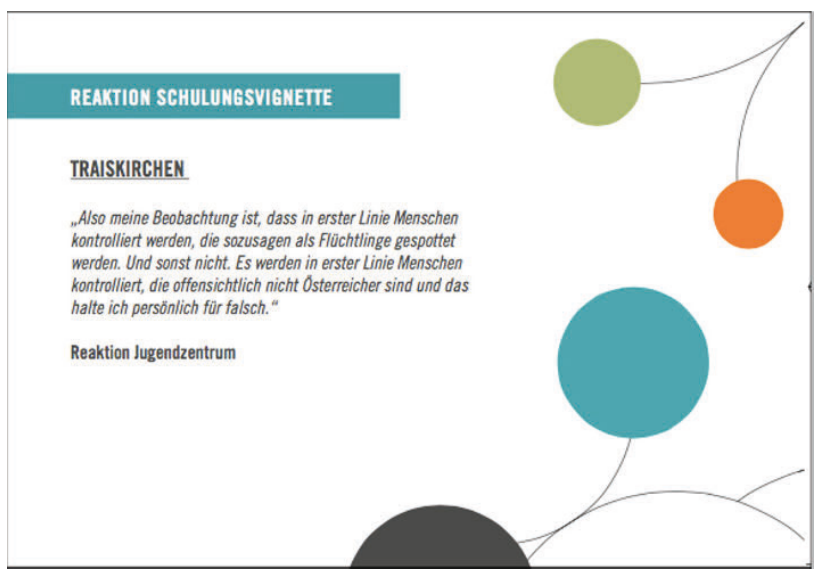

Die korrigierte Version des Kapitels ist verfügbar unter https://doi.org/10.1007/978-3-658-27305-7_7

(C) Springer Fachmedien Wiesbaden GmbH, ein Teil von Springer Nature 2019 